\title{
Olas migratorias en Colombia y su influencia sobre el rendimiento de la economía
}

\section{Migratory waves in Colombia and its influence on the performance of the economy}

\author{
Dina Luz Jiménez - Lobo', Juan Andrés Guerrero - Duran² \\ ${ }^{1}$ Grupo de Investigación ECONFI, Universidad Popular del Cesar-Seccional Aguachica, Colombia, \\ ORCID: https://orcid.org/0000-0001-6343-9844, E-mail: dljimenez@unicesar.edu.co \\ ${ }^{2}$ Grupo de Investigación ECONFI, Universidad Popular del Cesar-Seccional Aguachica, Colombia, \\ ORCID: https://orcid.org/0000-0002-3557-7972, E-mail: juanaguerrero@unicesar.edu.co
}

Cómo citar: Jiménez - Lobo, D. L., \& Guerrero - Duran, J. A. (2020). Olas migratorias en Colombia y su influencia sobre el rendimiento de la economía. Revista Científica Profundidad Construyendo Futuro, 13(13), 70-81. https://doi.org/10.22463/24221783.2660

Recibido: 27 de Mayo de 2020 / Aprobado: 18 de Junio de 2020

\begin{abstract}
Resumen
La migración es un fenómeno que ha evolucionado con el ser humano, se ha transformado a tal punto que se ha convertido en un modo de vida y de subsistencia. Colombia a lo largo de su historia ha sido participe de múltiples olas migratorias que han llevado a que pase de ser un país de origen que recibe remesas a ser un país receptor. Por lo que con este estudio, se busca determinar el rendimiento de la economía colombiana en cada una de las olas migratorias vividas desde 1996 hasta el 2019, para esto, se utilizó una metodología con un enfoque cuantitativo debido a que por medio de un análisis estadístico de correlación se determinó el grado de relación entre la variable dependiente Producto Interno Bruto y los movimientos migratorios efectuados de Colombia a Estados Unidos, Venezuela y España, así como, la entrada de extranjeros venezolanos a Colombia.
\end{abstract}

Palabra clave: Crecimiento económico; Mercado laboral; Migración; Producto interno bruto

\begin{abstract}
Migration is a phenomenon that has evolved with humans, it has been transformed to the point that it has become a way of life and subsistence. Throughout its history, Colombia has been a participant in multiple waves of migration that have led it to go from being a country of origin that receives remittances to being a receiving country. Therefore, this study seeks to determine the performance of the Colombian economy in each of the migratory waves experienced from 1996 to 2019, for this, a methodology with a quantitative approach was used due to the fact that through a statistical analysis Correlation was determined the degree of relationship between the dependent variable Gross Domestic Product and the migratory movements made from Colombia to the United States, Venezuela and Spain, as well as the entry of Venezuelan foreigners to Colombia.
\end{abstract}

Keyword: Economic growth; Labor market; Migration; Gross domestic product. 


\section{Introducción}

La migración es un fenómeno que radica en el desplazamiento de un lugar a otro en búsqueda de mejores oportunidades. La (Organización Internacional para las

Los continuos desplazamientos de personas a lo largo de la historia han dejado fuertes huellas en la economía, la cultura, y la política de las sociedades. Los desequilibrios que tienden a generar las migraciones son suavizados en su mayoría por la implementación de políticas que van direccionadas a atacar indicadores económicos y sociales. De ahí que resulta necesario analizar como las migraciones han influido en el crecimiento económico de los países, es decir, como los movimientos de personas logran influir en el rendimiento económico de una nación sobre todo si se tiene en cuenta que muchos de esos desplazamientos son de forma forzada, mientras otros son voluntarios.

Se entiende por migración forzada a aquel movimiento de personas en el que se observa la coacción y manipulación por medio de amenazas a la vida humana ya sea por medios naturales o humanos, y tienden a desplazarse a lugares que no son óptimos para mejorar su calidad de vida. Sin embargo, son una mejor opción que su lugar de origen. Mientras, que la migración voluntaria radica en movimientos de personas de forma espontánea lo cuales emigran sin asistencia, además tienden a escoger su destino en base a sus preferencias y oportunidades que este les ofrezca.

Las migraciones tienden a estar sujetas a la percepción del individuo o grupo familiar sobre un entorno y en la búsqueda de mejores oportunidades optan por desplazarse, ahora,
Migraciones, 2006) indica que la migración es un desplazamiento de individuos entre territorios con carácter de refugiados, exiliados económicos.

esos movimientos generan un impacto en la economía de los países receptores, pero también en la de los lugares de origen. Muchos países han sufrido graves problemas por los fuertes procesos migratorios, sin embargo, estos problemas tienden a agudizarse cuando la migración se presenta de manera forzada, limitando el crecimiento económico, generando incertidumbre entre los residentes e inmigrantes del país de destino.

Colombia es un país que se encuentra ubicado al norte del continente sur americano quien a lo largo de su historia ha presentado 4 olas migratorias de las cuales 3 de ellas han sido migraciones voluntarias o espontaneas, mientras que la última ola (4 ola migratoria) ha diferido en el hecho en que es forzada, pero, además, Colombia ya no es el país de origen sino el país receptor. Dichos movimientos migratorios se vieron incentivados por la búsqueda de mejores oportunidades como el llamado "Sueño Americano", así como la violencia armada que vivió el país durante más de 60 años.

Con el objetivo de Determinar el rendimiento de la economía colombiana desde 1996 hasta 2019 en relación a los movimientos migratorios que ha presentado Colombia como país de origen y receptor. Se busca, por medio de una medición estadística de correlación analizar la relación entre cada una de estas variables, para así, demostrar ¿cuáles son los efectos de una migración forzada en un país como Colombia donde los 
rendimientos de la economía no son óptimos?, todo esto con el fin de darle una explicación a este fenómeno demográfico que se ha acentuado en las últimas décadas.

\section{Marco teórico}

\subsection{Aspecto Teórico e histórico de la Migración}

La migración se ha convertido en un fuerte indicador de evolución y transformación del hombre, ya que logra medir la capacidad para relacionarnos y comunicarnos con personas de otras partes del mundo. Por lo que resulta ser un tema de mucho interés a nivel general, así como individual.

El concepto de migración resulta tener varios significados dependiendo de las áreas o enfoques de estudio. (Lewis, 1954) define la migración desde un enfoque macroeconómico más específicamente desde los intercambios laborales. Lo que significa que, si un país desarrollado ofrece mejores condiciones salariales que un país emergente, esto incentivara a la migración hacia el país desarrollado. Este tipo de migración suele presentarse de manera legal o ilegal. Para evitar que se presente estos desplazamientos, los países buscan desaparecer las brechas salariales a través de la regulación de los mercados laborales de los países de origen y los receptores.

Por su parte, la Teoría Neoclásica, aborda el tema migratorio desde un enfoque Microeconómico, donde exponen que la migración es un fenómeno que inicia como una acción espontanea del individuo, el cual busca que al desplazarse a otro lugar se pueda obtener un beneficio sobre sus costos. Según (Todaro, 1976), el individuo después de analizar sus posibilidades económicas migra hacia el lugar que les pueda maximizar en la mayor cantidad sus beneficios, ya sean monetarios o sociales, dichas ganancias se ven reflejados por medio de las características que poseen los individuos, ya sean de tipo social o tecnológicas, las cuales tienden a disminuir los costos de desplazamiento y por consiguiente se aumentan los beneficios. Los gobiernos buscan controlar la migración por medio de la implementación de políticas que logren afectar las utilidades o ganancias de los países de origen y/o países receptores.

La teoría neoclásica del capital humano y la nueva teoría de las migraciones poseen un mismo enfoque microeconómico, tal es el caso de (Piore \& Sabel, 1984), los cuales basan su teoría del trabajo dual más en el comportamiento del mercado laboral del país receptor que el del país de origen, ya que los inmigrantes buscan llenar los vacíos que existen el mercado de trabajo de países desarrollados, los cuales carecen de mano de obra debido a que los nativos no desean ocupar esos puestos de trabajo. Según (Pacheco Ríos, 2016) la limitación de la teoría del mercado dual radica en que solo se examina al país receptor más no al de origen.

La Teoría del sistema mundial al igual que la teoría del mercado dual, señala que la migración internacional busca ocupar los puestos de trabajo no deseadas por la población nativa, ya que, en muchos casos, tienden hacer trabajos que exigen mucha fuerza bruta o poseen a criterio de los locales un muy bajo salario.

$\mathrm{Y}$ es que, los inicios de las migraciones se remontan con el origen del ser humano, quien en búsqueda de sobrevivir comienza a desplazarse de un lugar a otro debido a la necesidad de alimentos que dependía de actividades como la caza, pesca, agricultura y la ganadería. Según un estudio realizado por 
el Colectivo Ioé ${ }^{1}$ la migración inicia con la especie de homínidos; una de las primeras especies que impulsaron la migración, esta subtribu de primates se caracterizó por caminar en dos patas y de manera vertical por lo que la búsqueda de alimentos llevo a que desplazase de un lugar a otro.

Gran parte de las primeras migraciones aún son desconocidas para el hombre dado que no existen evidencias históricas que las demuestren. Sin embargo, la arqueología ha logrado estudiar bastantes asentamientos humanos que permiten hacer una recopilación lo suficientemente buena como para plantear supuestos sobre este fenómeno.

Bob Sutcliffe explica de forma cronológica los diferentes asentamientos humanos que han existido a lo largo de la historia. El autor señala que desde el origen del ser humano en África hace aproximadamente unos 150.000 años, los primeros pobladores lograron emigrar a Asia Oriental hace alrededor de 90.000 años. De ahí, se logran encontrar evidencias de seres humanos en Europa Occidental, Siberia Central y Australia 50.000 años más tarde del último descubrimiento. Se cree que los humanos lograron llegar al territorio americano hace aproximadamente 15.000 años. Pero, las migraciones no cesaron ahí, el ser humano logro poblar cada uno de los continentes hoy conocidos.

La migración tomo mucha más fuerza con la llegada de las grandes civilizaciones mediterráneas tales como; Fenicia, Cartago, Grecia y Roma. Estas civilizaciones lograron organizar flujos emigratorios, utilizándolo como técnica para exportar ese excedente

1 Colectivo Ioé: Es un equipo de investigación social formado por Walter Actis, Miguel Ángel de Prada y Carlos Pereda. Se fundó en 1982 y cesó su actividad empresarial en social que se amontonaba en las fronteras interiores con el fin de garantizar el orden político de sus territorios.

Seguido de las civilizaciones, el proceso migratorio logra tener 3 periodos de grandes oleadas migratorias en la época capitalista. La primera ola corresponde a los siglos XVIXIX, durante este periodo se dio el descubrimiento y conquista de América, dando lugar a la esclavitud que se convirtió en uno de los procesos migratorios más grande de la historia, el cual estaba fundamentado en el comercio de esclavos que fueron llevados desde África hasta América.

Entre el siglo XVI y XVII inmigraron al nuevo mundo de 10 a 20 millones de personas de diferentes clases sociales, razas u origen. (Sutcliffe, 1998) en su ensayo "Nacidos en otra parte" explica que la primera ola migratoria en el capitalismo fue de tipo obligatoria para el migrante, ya que no era su deseo desplazarse a este lugar. La migración se debió a la supremacía de las necesidades de varios grupos, entre estos los dueños de las plantaciones en el nuevo mundo, los traficantes de esclavos, y por último se encuentran los caciques africanos que vendieron a los esclavos. Esta migración ha logrado dejar una herencia por lo que respecta a la estructura cultural y social de las poblaciones. Vale la pena aclarar, que los esclavos no fueron los únicos que inmigraron a América, muchos europeos también lo hicieron solo que las razones eran totalmente diferentes, era migración voluntaria en la mayoría de los casos.

2014; actualmente desarrolla su actividad en el seno del Grupo Cooperativo Tangente (Madrid). Uno de sus ejes de interés es fomentar el desarrollo de las iniciativas sociales y promover la participación de los colectivos implicados. 
La segunda ola de migración se dio a principios del siglo XVIII, llegando a su apogeo en los inicios del siglo XX, se debió a los desplazamientos de migrantes de Europa Occidental hacia América y Australia. (Sutcliffe, 1998) señala que a Argentina llegaron alrededor de 5,7 millones de personas entre 1857 y 1926 , mientras que a Brasil desde 1820 hasta 1970 ingresaron un total de 5,6 millones de inmigrantes, por su parte, a Canadá llegaron 6,6 millones entre 1831 y 1924, y a Estados Unidos llegaron 36 millones de personas en los años de 18201924.

Más de 60 millones de personas de Europa Occidental se trasladaron de manera permanente a América o Australasia debido a varios factores como; la desesperación; vivir una aventura en otro país desconocido, y la liberación. El hecho de que existieran diferentes razones esta ola migratoria, tiende a diferenciarla de las anteriores migraciones, sobre todo porque estas personas emigraron del continente con más desarrollo económico, además de que las consecuencias que se originaron en el país de origen y en el país receptor fueron muchísimas más profundas que las consecuencias de las anteriores oleadas migratorias, así como los efectos que se ocasionaron sobre la estructura étnica fueron también muy diferentes. Sin embargo, lo que más caracterizo este periodo migratorio fue el grado de "Elección" que tuvieron las personas para desplazarse de un lugar a otro. Esta última característica de la segunda oleada migratoria llevo a sentar las bases sobre la existencia de aspectos positivos en las ideas sobre la migración.

La tercera ola migratoria corresponde al periodo antes de la segunda guerra mundial, en el que países como India y China comenzaron a proveer de fuerza de trabajo a las plantaciones y minas de otros países tales como; Birmania, Singapur, Mauricio, Sudáfrica, Sri Lanka, Malacia, Jamaica y Guayana. A este proceso se le llamo "Siervo Temporero" en donde varios millones de personas de origen en su mayoría chino migraron a otros países para laborar por contratos cortos en su mayoría de 10 años, luego el migrante volvería a su país de origen. Sin embargo, muchos de estos siervos temporales no regresaron, llevando al nacimiento de una nueva clase obrera la cual no contaba con derechos políticos ni humanos que le garantizasen una adecuada calidad de vida, acuñando a esto el hecho de aun hoy día persisten en ciertas regiones personas con rasgos provenientes de la india y la china. Resumiendo, los tres periodos, se puede afirmar que; la primera ola migratoria fue de una migración forzada; la segunda ola fue de alguna forma una migración semi-forzada, y la última ola fue una migración de tipo voluntaria.

\subsection{Proceso Migratorio en Colombia}

En el caso de Colombia, este es un país que se ha caracterizado a lo largo de su historia por una gran movilidad de población, debido a varios condicionantes tales como; la situación económica y la baja calidad de vida de sus habitantes, así como la violencia armada que ha azotado por más de 60 años, así mismo, existen otros condicionantes como son la búsqueda de mejores oportunidades de vida y darle cumplimento a muchos sueños y anhelos de los colombianos. El proceso migratorio colombiano se ha caracterizado por presentar 4 grandes olas migratorias en donde ha pasado de ser país de origen a receptor.

El (Ministerio de Relaciones Exteriores, 2020), plantea que la primera ola migratoria está comprendida: 
"desde la década de los años sesenta, setenta y parte de los noventa, esta tiene que ver con las emigraciones de colombianos a los Estados Unidos. Las razones que motivaron esta migración se apoyaron en factores de tipo económicos, sobre todo, se relacionó con la posibilidad de encontrar un buen empleo y así aumentar sus ingresos" (pág.1).

Sin embargo, también existen razones de tipo políticas asociadas al conflicto armado que se vivía en Colombia en esas décadas sobre todo en los noventas debido a las amenazas por parte de grupos armados como las $\mathrm{FARC}^{2}$ o las $\mathrm{AUC}^{3}$ quienes dominaron al país en el siglo pasado. Esta primera ola se caracterizó por el alto nivel educativo con el que contaban los emigrantes, los cuales en su mayoría hablaban inglés, así mismo, el porcentaje de mujeres que salieron del país rumbo a E.E.U.U. fueron superiores al porcentaje de hombres. También fue más grande el porcentaje de personas de clase media y alta que el de clase baja. Dicha migración de colombianos ha disminuido a lo largo de los años, pero aún se sigue dando de manera constante.

La segunda Ola tiene que ver con las emigraciones que se provocaron en Colombia en los años 80 con destino a Venezuela, debido a que este país en los años 70 fue coparticipe de la creación de la organización de países exportadores de petróleo- OPEP, la cual propuso juntar a todos los países productores y exportadores de la mayor cantidad de petróleo en el mundo. La crisis económica de 1973 se produjo como consecuencia del alza en los precios del crudo, lo que género en los países petroleros una entrada masiva de divisas acompañado de un crecimiento y dinamismo económico

\footnotetext{
${ }^{2}$ Fuerzas Armadas Revolucionarias de Colombia
}

nunca antes visto en la región, convirtiéndose Venezuela en la economía más importante de américa latina, y por consiguiente un paraíso atractivo para los emigrantes colombianos.

Según (Prasca Aguilar, 2011) la migración de colombianos hacia Venezuela estuvo asociada con la crisis del petróleo en la década de los 70’s. Sin embargo, la autora aclara que la migración entre estos dos países es más proceso histórico que coyuntural. Ya que en 1976 y 1980, Venezuela crea una estrategia llamada el "Plan V" que consistía en invertir más en las empresas nacionales, impulsando a su vez al ahorro, con el fin de dinamizar la economía Interna, para esto Venezuela requería contratar aproximadamente un millón de trabajadores. Hasta octubre de 1977 Venezuela había logrado contratar 1.2 millones de trabajadores extranjeros de los cuales el casi el $60 \%$ eran de origen colombiano.

Esta segunda ola migratoria se dio con gran fuerza debido a que Venezuela ha sido un pais de puertas abiertas para los imigrantes, sumado a esto, el hecho de que el pais vecino gozaba de un buen estatus economico en el pasado siglo y se volvio un motor para la migracion laboral. Venezuela necesitaba mano de obra dispuesta a trabajar en todos los proyectos que demandaba, debido a esto, un gran numero de Colombianos vieron en venezuela la salida a muchos problemas, sobre todo el de violencia armada que vivia el pais en ese tiempo, esto incentivo la dictadura de Marcos Perez Jimenez.

Dado que la migracion de Colombianos al vecino pais se registro de forma opcional, ademas, que el pais de destino resultaba ser beneficioso para los migrantes se dio un tipo

${ }^{3}$ Autodefensas Unidas de Colombia 
de migracion llamada "migracion Voluntaria". Asi mismo, La tercera ola migratoria colombiana se dio desde 19981999 hacia España la cual se debió en gran parte a la crisis económica que enfrentaba el país, siendo en su mayoría los emigrantes del eje cafetero. Otra razón fue el hecho de que España representa un lugar atractivo para los inmigrantes en búsqueda de empleo, además de la facilidad idiomática que representa para los países de habla hispana.

Por otro lado, la ultima ola migratoria mas representaiva del pais modifico el escenario que habia representado Colombia en los ultimos años, es decir, paso de ser pais de origen a pais receptor. Todo inicia debido a que las relaciones entre venezuela y Colombia han sido tan fuerte al punto que aparte de la segunda ola migratoria hoy día se este presentando una cuarta ola migratoria, pero las condiciones son totalmente distintas. La migracion voluntaria de los años 80 es difiere completamente a la migracion forsoza iniciada en el año 2012 cuando el deterioro de los indicadores macroeconomicos avisaron sobre lo que hoy se conoce como la "Depresion Economica Venezolana", dando inicio a la cuarta ola migratoria de Colombia. El problema está, en que esta a diferencia de las pasadas 3 olas, esta migracion resulto ser de tipo "Migracion Forzada" ademas de que Colombia paso de ser el pais de origen a pais receptor y no contaba con las condiciones para recibir inmigrantes.

En la Figura 1 se puede evidenciar el comportamiento de las salidas de Colombianos a Estados Unidos, Venezuela y España desde 1996, y la entrada de exranjeros provenientes de Venezuela desde el 2012. Según datos extraidos de (Departamento Administrativo Nacional de EstadísticasDANE, 2003-2012) y (Migración Colombia, 2020), la primera ola migratoria que fue hacia
Estados Unidos aún sigue presente debido a la importancia comercial de este pais con Colombia. Los movimientos migratorios hacia E.E.U.U. han presentado aumentos sustantivos desde 1960 hasta la actualidad. A fecha del 2019, la migracion de colombianos E.E.U.U. represento un gran porcentaje de los movimientos migratorios, pero, fue superado por los movimientos registrados por los ciudadanos venezolanos.

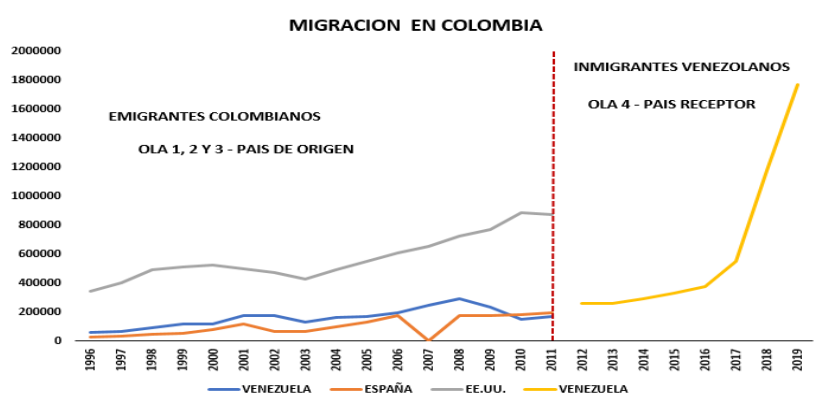

Figura 1. Comportamientos de los movimientos migratorios en Colombia. Fuente: Histórico-Anuario Estadístico de los movimientos internacionales-DANE (2003-2012). Radiografías de la Migración de venezolanos- Migración Colombia (2017-2019).

Las migraciones traen consigo una serie una beneficios para las eonomías de los paises receptores asi como para los de origen. Una forma de medir esos rendimientos es por medio de las Remesas. Las cuales, son las ganacias que envian los inmigrantes a su pais de origen.

La remesas son transferencias giradas por los inmigrantes a su pais de origen. Según (Bedoya Rangel \& Jáuregui Díaz, 2016), este tipo de ingresos reflejan los vinculos sociales de una persona con su pais y su familia, convirteindose en el motor economico que impulsa a las migraciones, creando asu vez una relación con la economía del pais donde labora y del cual extrae el recurso, asi como, en el pais que recibe la transferencia.

La migración trae consigo un aumento de la mano de obra y el abaratamiento de esta en 
los paises de destino, lo cual puede aumentar la productividad de este o desencanar un crisis salarial que dejaria a los inmigrantes y nacionales por fuera del mercado laboral, debido a que aumenta la competencia. Mientras, que en los paises de origen, puede que aumente el precio de la mano de obra por la disminución de poblacion generando una caida de la producción o mejores oportunidades en el mercado laboral.

Permitiendo de esta forma, que medir el rendimiento de una economía debido a los movimientos migratorios resulte complejo por la cantidad de variables que se modifican por los aumentos o disminuciones de población. Sin embargo, con este estudio lo que se busca es simplemente medir el grado de correlacion entre las dos variables teniendo en cuenta los dos moemntos en los que se ubico el pais en los ultimos 24 años como pais receptor y de origen.

\section{Metodología}

Para analizar la influencia de las olas migratorias que se han presentado a lo largo de la historia de Colombia sobre la economía es necesario aplicar una metodologia con un enfoque cuantitativo debido a que se planea observar el comportamiento de diferentes variables, en dos etapas. Primero, se analizara la correlacion entre el PIB y salida de colombianos a España, Estados Unidos y Venezuela desde 1996 hasta 2011. Segundo, se medira la correlación entre el PIB y la entrada de venezolanos a colombia desde el 2012 hasta el 2019.

Siguiendo la linea metodologica expuesta por (Hernández Sampieri, Fernández collado, \& Baptista Lucio, 2014) el diseño de investigación que se aplicara sera de tipo No experimental ya que se busca observar el fenomeno migratorio y su incidencia sobre la economía del país, para esto se realizara una investigación Transeccional dado que se planea analizar el fenomeno migratorio en un momento especifico que va de 1996-2019, con un alcance de tipo correlacional dado que se busca demostrar el grado de correlación entre las variables estudiadas.

Para analizar el nivel de correlación entre las variables observadas se utilizara la medición establecida por (Hernández Sampieri, Fernández collado, \& Baptista Lucio, 2014) formulado en la tabla 1 que muestra los diferentes grados de correlacion, en el cual se detalla el rango de valores que oscilan entre $-1 \mathrm{y}+1$, donde -1.00 es una correlación negativa perfecta, cero (0) que no existe una correlación entre las variables y +1 una correlación positiva perfecta (ver tabla 1).

Tabla 1. Baremo de Interpretación para el coeficiente de Pearson

\begin{tabular}{cl}
\hline \multicolumn{2}{c}{ Interpretación para el coeficiente de } \\
Pearson \\
Rango & \multicolumn{1}{c}{ Magnitud } \\
\hline-1.00 & Correlación negativa perfecta \\
-0.90 & $\begin{array}{l}\text { Correlación negativa muy fuerte } \\
\text { negativa }\end{array}$ \\
-0.75 & $\begin{array}{l}\text { Correlación } \\
\text { considerable }\end{array}$ \\
-0.50 & Correlación negativa media \\
-0.25 & Correlación negativa débil \\
-0.10 & Correlación negativa muy débil \\
0.00 & No existe correlación alguna \\
+0.10 & entre las variables \\
+0.25 & Correlación positiva muy débil \\
+0.50 & Correlación positiva débil \\
+0.75 & Correlación positiva media \\
+0.90 & Correlación positiva muy fuerte \\
+1.00 & Correlación positiva perfecta \\
\hline
\end{tabular}

Fuente: Hernández, Fernández y Baptista (2014). 
Formulas a Utilizar

$$
\begin{array}{r}
r_{x y}=\frac{\sum x_{i} y_{i}-n \bar{x} \bar{y}}{n s_{x} s_{y}} \\
\frac{n \sum x_{i} y_{i}-\sum x_{i} \sum y_{i}}{\sqrt{n \sum x_{i}^{2}-\left(\sum x_{i}\right)^{2}} \sqrt{n \sum y_{i}^{2}-\left(\sum y_{i}\right)^{2}}}
\end{array}
$$

Fuente: Hernández, Fernández y Baptista (2010). Formula simplificada

$$
r=\frac{s_{x y}}{s_{x} s_{y}}
$$

Donde:

$$
\mathrm{S}_{\mathrm{xy}}=\text { Covarianza de } \mathrm{xy}
$$

$\mathrm{S}_{\mathrm{x}} \mathrm{S}_{\mathrm{y}}=$ Desviación estándar de $\mathrm{x}$ multiplicado por desviación estándar de y

En cuanto a la Tecnica de recoleccion de datos se aplicara una de analitica, ya que se realizara un analisis de documentos, para esto se utilizara como herramienta excel, el cual permite medir estadisticamente el grado de correlacion entre el PIB y salida de colombianos con destino a Estados Unidos, Venezuela y España, asi como la relacion del Producto Interno Bruto con la entrada de inmigrantes de venezolanos al territorio Colombiano.

\section{Resultados}

Las olas migratorias en Colombia han repercutido significativamente en el comportamiento de la economía del pais. Se han efectuado cambios en los movimientos migratorios que han dejado reflejado la incapacidad de colombia para hacer frente a grandes cambios poblacionales cuando se es pais de destino, sobre todo, tomando como base que los desplazamiento forzados generan indicadores negativos en la economia, tales como desempleo, inflación, descrecimiento economico, etc.

El ccoeficiente de correlación entre PIB y emigrantes colombianos durante las olas 1,2 y 3 con destino a estados unidos, España y Venezuela es de $+0,9$. Lo que significa que desde 1996 hasta 2011 el PIB de Colombia creció mientras aumentaba el número de salida de colombianos con destino a Estados Unidos, España y Venezuela. Este comportamiento se debió en parte al ingreso de remesas provenientes de estos países.

$$
\begin{gathered}
r=\frac{s_{x y}}{s_{x} s_{y}} \quad(2-a) \\
r=\frac{1,85842 E+16}{2,04945 E+16}=0,906788025
\end{gathered}
$$

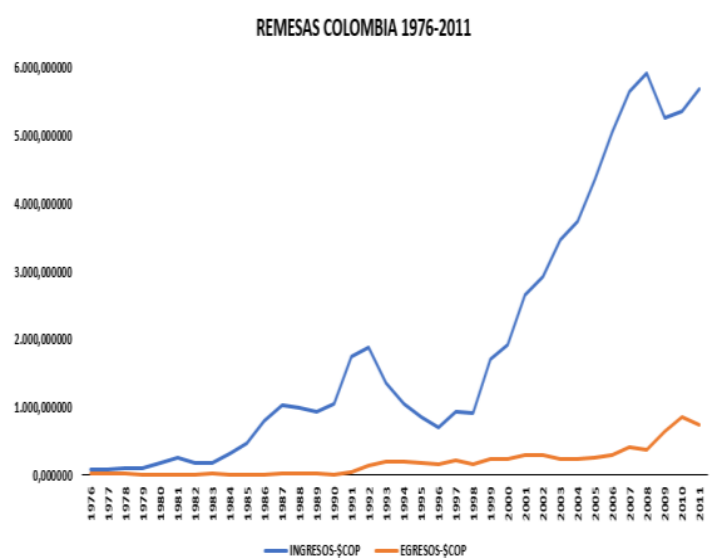

Figura 2. Comportamiento de Remesas en Colombia (1976-2011). Fuente: Histórico-Anuario Estadístico del DNP (1976-2011).

El comportamiento de Remesas en Colombia desde 1996 (ver figura 2) se puede observar como el ingreso de remesas presentaba una caida. Sin embargo, estaba por encima del egreso de remesas. Pero, a lo largo de los ultimos años, aumento sustancialmente hasta el año 2011. Los años posteriores, Colombia registro movimientos 
muy similares conrespecto al ingreso de remesas y salida de remesas.

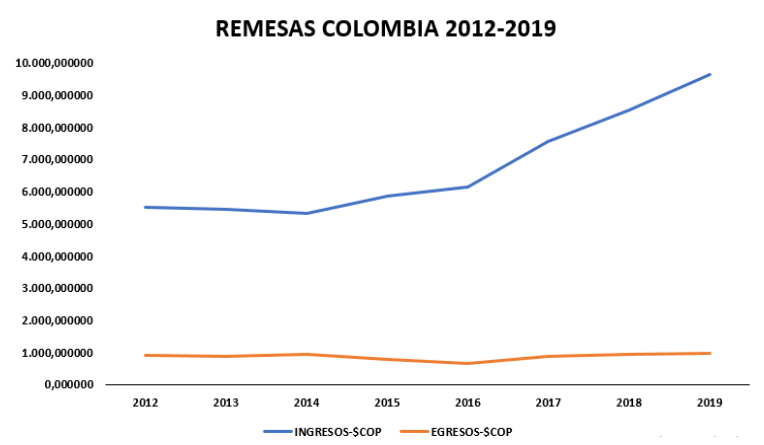

Figura 3. Comportamiento de Remesas en Colombia (2012-2019). Fuente: Histórico-Anuario Estadístico del DNP (2012-2019).

Lo que significa que la salida de remesas no presento cambios sustanciales con el aumento de venezolanos que ingresaron al pais. Como resultado, el grado de correlacion entre la entrada de extrajeros provenientes de Venezuela y el PIB fue de $-0,21$, siendo un puntaje de correlacion negativa debil, que significa que un aumento de inmigrantes de venezolanos genero una caida de la produccion-PIB, es decir, un decrecimiento de la economía colombiana, pero de poco alcalce, y profundidad, producto del aumento del desempleo debido aun crisis laboral que enfrenta Colombia desde el 2012 con el inicio del exodo venezolano.

$$
\begin{gathered}
r=\frac{\mathrm{s}_{\mathrm{xy}}}{\mathrm{s}_{\mathrm{X}} \mathrm{S}_{\mathrm{y}}} \\
\mathrm{r}=\frac{-4,62204 E+15}{2,16884 E+16}=-0,213111043 \text { (2-b) } \\
\mathrm{s}_{\mathrm{xy}}=\text { covarianza de } x y \\
\mathrm{~s}_{\mathrm{x}} \mathrm{s}_{\mathrm{y}}=\text { desviacion estandar de } x \text { multiplicado por } y
\end{gathered}
$$

(Fedesarrollo, 2018), en un estudio realizado sobre el mercado laboral y la migración de venezolanos a Colombia señalo que:

"El $72 \%$ de la población de origen venezolano se encuentra activa en el mercado laboral, mientras que, de la población colombiana solo el $64 \%$ se encuentra laborando, resultado del abaratamiento de la mano de obra y el aumento de la competencia aunado a la premura de las necesidades de esta población su participación es mucho más alta” (pág. 4).

\section{Discusiones}

La teoría económica indica que las migraciones forzosas tienden a generar un decrecimiento en la economía del país receptor, por lo que, en base a lo analizado en la correlación de las variables (PIB, entrada y salida de inmigrantes) en cada una de las olas migratorias se evidencio claramente que; primeo que todo, el hecho de que la cuarta ola posea el condicionante de ser una migración forzada donde muchos ciudadanos venezolanos debieron salir de su país rumbo a Colombia sin muchas opciones y bajo una presión económica, además que el país de destino no contaba con una economía lo suficiente mente fuerte para recibir tantas personas.

Esto genero según lo observado en la ecuación 2(a), un decrecimiento en la economía colombiana desde el 2012 hasta el 2019 que fue donde se agudizo el éxodo venezolano, que si bien, el índice de correlación es débil, aun muestra un comportamiento inversamente proporcional entre las variables estudiadas. Por lo que se cumple la teoría económica de que al aumentar el número inmigrantes en un país de 
bajos recursos como Colombia la tendencia del PIB es a la baja.

\section{Conclusiones}

Para finalizar, se puede concluir que la economía colombiana durante las tres primeras olas de migracion en donde el pais tenia una posicion de origen, el crecimiento anual del PIB sostuvo una relacion positiva con los ingresos de remesas, esto entendido a que como pais de origen las tres primeras olas migratorias los ciudadanos colombianos salieron de forma voluntaria del pais $y$ realizaban trasferencias hacia el mismo. Por el contrario, durante la cuarta ola en donde el papel de colombia cambia a pais receptor de inmigrantes y esto debido a una dificil situacion socioeconomica que presenta el vecino pais de venezuela, aumenta significativamente la mano de obra disponible en el pais, generando un desplazamiento de la mano de obra local por el abaratamiento de la misma entendido como una consecuencia de migracion forzosa, provocando un decrecimiento del PIB, que se agudizo debido a la crisis del petroleo y prostestas de diferentes sectores economicos en el pais.

\section{Referencias}

Bedoya Rangel, Y., \& Jáuregui Díaz, J. A. (2016). La recepción de Remesas Familiares internacionales y su impacto en la economía doméstica en Santiago de Cali, Colombia. Revista Colomb. Soc. , 243-262.

Colectivo Ioé. (1982). Inmigrantes, Trabajadores, Ciudadanos: una visión de las migraciones desde
España. Madrid: Patronat Sud-Nord de la Universidad de Valéncia.

Departamento Administrativo Nacional de Estadísticas-DANE. (2003-2012). Históricos-Anuarios Estadísticos de movimientos internacionales. Bogotá: DANE.

Fedesarrollo. (2018). Informe mensual del mercado laboral: Migración venezolana a Colombia. Bogotá: Fedesarrollo, ACRIP .

Hernández Sampieri, R., Fernández collado, C., \& Baptista Lucio, P. (2014). Metodología de la Investigación. Ciudad de México: McGraw Hill Education.

Lewis, W. A. (1954). Desarrollo Economico con oferta ilimitada de mano de obra.

Migración Colombia. (2020). Radiografías de los movimientos migratorios de venezolanos. Bogotá: Migración Colombia.

Ministerio de Relaciones Exteriores. (09 de 07 de 2020). Cancilleria de Colombia. Obtenido de Antecedentes Históricos y causas de la Migración: https://www.cancilleria.gov.co

Organización Internacional para las Migraciones. (2006). Glosario sobre Migración. Ginebra-Suiza: Organización Internacional para las Migraciones.

Pacheco Ríos, G. (2016). Idas y Venidas: El flujo Migratorio entre Colombia y Venezuela 1999-2015. Bogotá, Colombia. 
Piore, M. J., \& Sabel, C. (1984). La segunda división Industrial: Posibilidades de Prosperidad. Nueva York: Libros Básicos.

Prasca Aguilar, S. M. (2011). Migración Bolivarense a Venezuela entre 19701980: Un perfil del Fenómeno Migratorio legal e ilegal en la frontera Colombo-Venezolana. Cartagena de Indias , Bolivar, Colombia: Universidad de Cartagena.

Sutcliffe, B. (1998). Nacido en otra parte. Un ensayo sobre la migración internacional, el desarrollo y la equidad. Bilbao, Vizcaya, España.

Todaro, M. (1976). Migración interna en países en desarrollo: una revisión de la teoría, la evidencia, la metodología y las prioridades de investigación. Nueva York: Oficina Internacional del Trabajo. 